\title{
A Primer on Cointegration: Application to Nigerian Gross Domestic Product and Export.
}

\author{
A.G Ibraheem, A.A Adetunji \\ Department Of Mathematics And Statistics Federal Polytechnic, Ado-Ekiti - Nigeria
}

\begin{abstract}
This paper examines Gross Domestic Product (GDP) and Export (EXP) of Nigeria between 1970 and 2007 using data from Central Bank of Nigeria's Statistical Bulletin of 2008 for cointegration. Applying Autocorrelation Function (ACF), we find that each of the variables (GDP and Export) is non-stationary. Augmented Engle-Granger reveals that the regression of GDP on Export is actually cointegrated and not spurious. An error correction model shows that GDP does not adjust to change in EXP in the same time period. The regression model obtained also shows that the short-run changes in EXP have a positive impact on the short-run changes in GDP.
\end{abstract}

Keywords: Autocorrelation function, Export, Gross Domestic Product, stationarity, trend.

\section{Introduction}

The phenomenon of spurious or nonsense regression was first discovered by Yule (1926). He shows that (spurious) correlation could persist in non-stationary time series even with a very large sample. According to Granger and Newbold (1974), coefficient of determination denoted by $R^{2}$ greater than Durbin-Watson $d$ statistic is a good rule of thumb that the estimated regression is spurious. Dickey and Fuller (1979) show that in a model such as: $\Delta Y_{t}=\beta_{0}+\beta_{1} t+\delta Y_{t-1}+\alpha \Delta Y_{t-1}+\varepsilon_{t}$, under the null hypothesis that $\delta=0$, the estimated $t$ value of the coefficient of $Y_{t-1}$ follows the $\tau$ (tau) statistic. These authors compute the critical values of the tau statistic on the basis of Monte Carlo simulations.

Two variables are said to be cointegrated if they have a long-term or equilibrium relationship between them. The concept of cointegration occurs when a unit root time series is regressed on another unit root time series. The linear combination cancels out the stochastic trends in the two series.

Pandey (2006) focuses on the cointegration between Export and Gross Domestic Product and its components at current and constant prices using time series data for Export and Gross Domestic Product and its components for the period 1950/1951 to 2001/2002. In the long run, Export and GDP at constant prices are not cointegrable while export and GDP at current prices are cointegrable with positive direction of causality. In the short run, through error correction mechanism, he observes that the relationship between GDP and export shows that short run changes in export positively affects GDP and its components.

Gujarati and Sangeetha (2007) use Autocorrelation Function (ACF) and Augmented Dickey Fuller (ADF) to test the stationarity of U.S. Personal Consumption Expenditure (PCE) and U.S. Personal Disposable Income (PDI) from 1970 to 1991 . The two variables are individually found to be non-stationary. A further test of cointegration using Augmented Engle-Granger and Cointegrating Regression Durbin-Watson tests indicates that the variables are cointegrated. Hence, they conclude that the regression model obtained from regressing PCE on PDI is not spurious but cointegrating.

Drama and Yao (2011) demonstrate that there is a long run equilibrium relationship between money supply (M1) and its main determinants, real income (GDP) and interest rate in Cote d'Ivoire. In order to investigate long-term relationship among these variables, they use Juselius and Johansen cointegration test with time series data from the period of 1980 to 2007 (Juselius and Johansen, 1990). The results show that there is long-term relationship among these variables as well as the linkage between them. Based on this result, they show that only real money balances has significant long -run economic impact of variations in monetary policy in Cote d'Ivoire. The study also reveal that the effect of aggregate is not stable linking with it determinants.

Amzath et al (2010) investigate the effect of real exchange rate on the balance of trade of Cote d'Ivoire using multivariate cointegration tests and vector error correction models with time series data between the period of 1975 to 2007. Their results confirm the existence of long-run relationships among Trade Balance (TB), Real Exchange Rate (RER) and foreign and domestic incomes for Cote d'Ivoire. Estimated results also demonstrate that the Real Exchange Rate has a significant positive influence on Cote d'Ivoire's trade balance in both short and long-run under fixed real exchange rate management policies for the considered period. The Granger Causality test shows that Real Exchange Rate causes the trade balance then based on the estimations, the Marshall-Lerner condition in Cote d'Ivoire's data is explored by utilizing the Impulse Response Function (IFR) which traces the effect of (RER) on the trade balance viewing the J-curve pattern. 
Husein (2009) examines export led-growth (ELG) hypothesis for Jordan in a multivariate framework by including terms of trade as a third variable and by using available annual data (1969-2005). He utilized Johansen, Saikkonen and Lütkepohl cointegration procedures and error correction modeling to test long-run and short-run relations between GDP, exports, and terms of trade. The study finds that real GDP, real exports, and terms of trade are cointegrated. The evidence suggests long-run bi-directional causality between real exports and real GDP. The results of this study suggest that promoting exports via export promotion policies will contribute to economic growth in Jordan.

Sudhakar and Jacob (2005) use stationarity, cointegration, and Granger causality tests to analyze the relationship between exports and economic growth in India over the pre-liberalization period (1960-1992). The analysis was conducted within a rigorous econometric framework that accounts for optimal lag selection and simultaneity bias. They find strong support for uni-directional causality from exports to economic growth using Granger causality regressions based on stationary variables, with and without an error-correction term. Unlike previous studies which ignore such fundamental issues as export-economic growth simultaneity, they used a Seemingly Unrelated Regression (SUR) procedure to account for possible simultaneity bias between exports and economic growth.

\section{Materials and Method}

The data set used for this research work is Nigeria's GDP and Export from 1970 to 2007 as obtained from Central Bank of Nigeria's Statistical Bulletin, 2008.

One of the simple tests of stationarity is the autocorrelation function (ACF). The ACF at lag $k$, denoted by $\rho_{k}$, is defined as

$\rho_{k}=\frac{\gamma_{k}}{\gamma_{0}}$, where $Y_{k}$ is the covariance at lag $\mathrm{k}$ and $Y_{0}$ is the variance

The values of $\rho_{k}$ lies between -1 and +1 as any correlation coefficient does. In any time series, if the autocorrelation at various lags hover around zero, such series is said to be stationary. However, if the autocorrelation coefficients at various lags are very high and possibly declining as the lag lengthens, such series are non-stationary. To test for stationarity of GDP and EXP using Autocorrelation Function (ACF), a rule of thumb is to compute ACF up to one-third to one-quarter the lag length of the time series. Since both variables under consideration are 38 years, by this rule lag length 12 will be sufficient.

A number of methods for testing cointegration have been proposed in literatures. This paper uses the method of Augmented Engle-Granger to test whether the two variables under consideration (GDP and Export) are cointegrated. In order to use the method, GDP is regressed on EXP using the model $G D P_{t}=\beta_{0}+\beta_{1} E X P_{t}+u_{t}$. The estimated residuals from this model, $\hat{u}_{t}$, is regressed on its lag-one period, $\hat{u}_{t-1}$. The t-statistic obtained as the coefficient of $\hat{u}_{t-1}$ is then compared with the Engle-Granger critical value. In absolute term, if the computed t-statistic is greater than Engle-Granger critical value, one can conclude that the regression of a non-stationary series (like GDP) on another non-stationary series (like Export) is cointegrating and not spurious and hence, the residuals are stationary i.e. I(0).

\section{Results and Discussion}

Using SPSS 17, the table below gives the Autocorrelation of GDP and EXP.

\begin{tabular}{|l|r|r|r|r|r|}
\hline & & & \multicolumn{3}{|c|}{ Box-Ljung Statistic } \\
\cline { 3 - 5 } Lag & Autocorrelation & Std. Error $^{\mathrm{a}}$ & Value & $\mathrm{df}$ & Sig. \\
\hline 1 & .773 & .162 & 24.520 & 1 & .000 \\
2 & .586 & .240 & 38.998 & 2 & .000 \\
3 & .416 & .275 & 46.500 & 3 & .000 \\
4 & .293 & .291 & 50.337 & 4 & .000 \\
5 & .256 & .299 & 53.352 & 5 & .000 \\
6 & .200 & .305 & 55.252 & 6 & .000 \\
7 & .150 & .308 & 56.355 & 7 & .000 \\
8 & .103 & .310 & 56.890 & 8 & .000 \\
9 & .075 & .311 & 57.183 & 9 & .000 \\
10 & .049 & .311 & 57.316 & 10 & .000 \\
11 & .015 & .312 & 57.329 & 11 & .000 \\
12 &. .025 & .312 & 57.366 & 12 & .000 \\
\hline
\end{tabular}


a. The underlying process assumed is MA with the order equal to the lag number minus one. The Bartlett approximation is used.

b. Based on the asymptotic chi-square approximation.

Table 1: Autocorrelations: Series: GDP

\begin{tabular}{|l|r|r|r|r|r|}
\hline & & & \multicolumn{3}{|c|}{ Box-Ljung Statistic } \\
\cline { 3 - 5 } Lag & Autocorrelation & Std. Error & Value & $\mathrm{df}$ & Sig. \\
\hline 1 & .772 & .162 & 24.491 & 1 & .000 \\
2 & .642 & .240 & 41.891 & 2 & .000 \\
3 & .457 & .282 & 50.972 & 3 & .000 \\
4 & .328 & .301 & 55.787 & 4 & .000 \\
5 & .249 & .310 & 58.653 & 5 & .000 \\
6 & .207 & .315 & 60.694 & 6 & .000 \\
7 & .163 & .319 & 61.991 & 7 & .000 \\
8 & .114 & .321 & 62.653 & 8 & .000 \\
9 & .085 & .322 & 63.031 & 9 & .000 \\
10 & .071 & .323 & 63.308 & 10 & .000 \\
11 & .028 & .323 & 63.351 & 11 & .000 \\
12 &. .023 & .323 & 63.383 & 12 & .000 \\
\hline
\end{tabular}

a. The underlying process assumed is MA with the order equal to the lag number minus one. The Bartlett approximation is used.

b. Based on the asymptotic chi-square approximation.

\section{Table 2: Autocorrelations: Series: EXPORT}

Since the autocorrelation coefficient starts at a very high value at lag 1 for both GDP and EXP and declines rapidly as the lag lengthens, this indicates that both GDP and EXP are non-stationary series. (Gujarati and Sangeetha, 2007).

Since it has been found that the variables (GDP and EXP) are individually non-stationary, Augmented EngleGranger test of cointegration is further used to test if they are cointegrated.

Regressing the GDP on EXP using SPSS 17 gives the table below:

\begin{tabular}{l} 
Model Summary ${ }^{\mathbf{b}}$ \\
\begin{tabular}{|l|r|r|r|r|r|}
\hline Model & $\mathrm{R}$ & R Square & Adjusted R Square & Std. Error of the Estimate & Durbin-Watson \\
\hline 1 & $.991^{\mathrm{a}}$ & .982 & .981 & $7.51225 \mathrm{E} 5$ & 1.877 \\
\hline
\end{tabular} \\
\hline
\end{tabular}

Table 3: Model Summary table for regression of GDP on EXP.

\begin{tabular}{|c|c|c|c|c|c|c|}
\hline & Model & Sum of Squares & $\mathrm{df}$ & Mean Square & $\mathrm{F}$ & Sig. \\
\hline \multirow[t]{3}{*}{1} & Regression & $1.096 \mathrm{E} 15$ & 1 & \multirow{3}{*}{$\begin{array}{l}1.096 \mathrm{E} 15 \\
5.643 \mathrm{E} 11\end{array}$} & \multirow[t]{3}{*}{1942.379} & \multirow[t]{3}{*}{$.000^{\circ}$} \\
\hline & Residual & $2.032 \mathrm{E} 13$ & 36 & & & \\
\hline & Total & $1.116 \mathrm{E} 15$ & 37 & & & \\
\hline
\end{tabular}

Table 4: ANOVA table for regression of GDP on EXP.

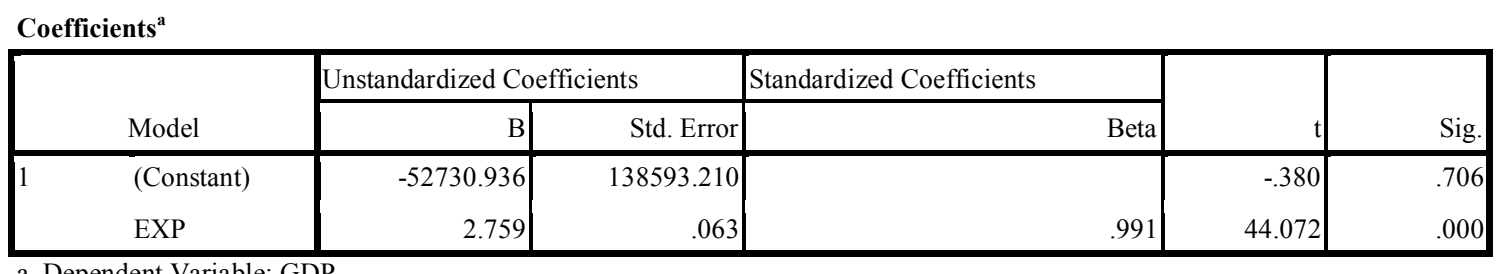

a. Dependent Variable: GDP

Table 5: Coefficients for regression of GDP on EXP.

Table 3 shows adjusted coefficient of determination of 0.981 indicating that $98.1 \%$ of GDP is explained by EXP. This is also supported by table 4 where the overall regression is statistically significant. From table of coefficient of regression (table 5), the model for regression of GDP on EXP is 
$G D P_{t}=-52730.936+2.759 E X P_{t}$. This model indicates a positive relationship between GDP and EXP.

To be certain that the regression model obtained above is not spurious, since both are non-stationary, a unit root test on the residuals obtained from this regression is performed, that is, we run the regression $\Delta \hat{u}_{t}=\delta \hat{u}_{t-1}+\varepsilon_{t}$, where $\Delta \hat{u}_{t}=\hat{u}_{t}-\hat{u}_{t-1}, \hat{u}_{t-1}$ is lag 1 of the residuals, and $\varepsilon_{t}$ is the random error term.

Running the regression $\Delta \hat{u}_{t}=\delta \hat{u}_{t-1}+\varepsilon_{t}$ using SPSS 17 gives the tables below:

Model Summary ${ }^{\mathrm{b}}$

\begin{tabular}{|c|c|c|c|c|c|}
\hline Model & $\mathrm{R}$ & R Square & Adjusted R Square & Std. Error of the Estimate & Durbin-Watson \\
\hline 1 & $.684^{\mathrm{a}}$ & .468 & .453 & $7.61158 \mathrm{E} 5$ & 1.949 \\
\hline
\end{tabular}

a. Predictors: (Constant), Residuals Lag 1: b. Dependent Variable: First Diff. Residuals

Table 6: Model Summary for regression of first-differenced error term on lag 1 error.

Coefficients $^{\mathrm{a}}$

\begin{tabular}{|c|c|c|c|c|c|}
\hline \multirow[b]{2}{*}{ Model } & \multicolumn{2}{|c|}{ Unstandardized Coefficients } & Standardized Coefficients & \multirow[b]{2}{*}{$\mathrm{t}$} & \multirow[b]{2}{*}{ Sig. } \\
\hline & $\mathrm{B}$ & Std. Error & Beta & & \\
\hline (Constant) & -444.645 & 125206.485 & & -.004 & .997 \\
\hline Residuals Lag 1 & -.957 & .173 & -.684 & -5.548 & .000 \\
\hline
\end{tabular}

a. Dependent Variable: First Diff. Residuals

Table 7: Coefficients for regression of first-differenced error term on lag 1 error.

From the table above, the regression model is $\Delta \hat{u}_{t}=-444.645-0.957 \hat{u}_{t-1}$. Since the Sig. value (.000) of the regression coefficient in the table is lesser than level of significance (.05), it can be concluded that the residuals from the regression of GDP on EXP are I(0); that is, they are stationary. Hence, the regression model $G D P_{t}=-52730.936+2.759 E X P_{t}$ is not spurious, even though individually the two variables are nonstationary. Therefore, the regression model is a cointegrating regression and its parameters can be interpreted as long run parameters and hence, the model specified for their relationship will be stable for control action and prediction purpose.

\section{Error Correction Model}

Since GDP and EXP are cointegrated, there is a long term or equilibrium relationship between the two. There may however be disequilibrium in the short run. Hence, error term can be treated as "equilibrium error". This error term can be used to tie the short run behavior of GDP to its long run value.

Sargan (1984) first used this error correction mechanism and it was later popularized by Engle and Granger (1987). Granger representation theorem states that if two variables are cointegrated, then the relationship between the two can be expressed as Error Correction Model (Granger, 1986). Hence, in $\Delta G D P_{t}=\alpha_{0}+\alpha_{1} \Delta E X P_{t}+\alpha_{2} u_{t-1}+\varepsilon_{t}$, ( $\Delta$ is the first difference operator, $\varepsilon_{t}$ is the random error term, and $u_{t-1}=G D P_{t-1}-\beta_{0}-\beta_{1} E X P_{t-1}$, that is, one-period lagged value of the error from the cointegrating regression), $G D P_{t}=\beta_{0}+\beta_{1} E X P_{t}+u_{t}$. The absolute value of $\alpha_{2}$ in the regression $\Delta G D P_{t}=\alpha_{0}+\alpha_{1} \Delta E X P_{t}+\alpha_{2} u_{t-1}+\varepsilon_{t}$ decides how quickly the equilibrium is restored.

The tables below show SPSS output of regression of $\triangle G D P_{t}$ on $\triangle E X P_{t}$ and $u_{t-1}$

Model Summary

\begin{tabular}{|l|r|r|r|r|r|}
\hline Model & $\mathrm{R}$ & R Square & Adjusted R Square & Std. Error of the Estimate & Durbin-Watson \\
\hline 1 & $.886^{\mathrm{a}}$ & .785 & .772 & $6.55897 \mathrm{E} 5$ & 1.423 \\
\hline
\end{tabular}

a. Predictors: (Constant), Residual Lag 1, First Diff. EXP: b. Dependent Variable: First Diff. GDP

Table 8: Model Summary for regression of first-differenced GDP on first diff. EXP and lag 1 Residuals. ANOVA $^{\text {b }}$

\begin{tabular}{|ll|r|r|r|r|r|}
\hline \multicolumn{1}{|c|}{ Model } & Sum of Squares & Df & Mean Square & $\mathrm{F}$ & Sig. \\
\hline 1 & Regression & $5.329 \mathrm{E} 13$ & 2 & $2.664 \mathrm{E} 13$ & 61.933 & $.000^{\mathrm{a}}$ \\
& $1.463 \mathrm{E} 13$ & 34 & $4.302 \mathrm{E} 11$ & & \\
Residual & $6.791 \mathrm{E} 13$ & 36 & & & \\
\hline
\end{tabular}

a. Predictors: (Constant), Residual Lag 1, First Diff. EXP: b. Dependent Variable: First Diff. GDP 
Table 9: ANOVA for regression of first-differenced GDP on first diff. EXP and lag 1 Residuals.

Coefficients $^{\mathrm{a}}$

\begin{tabular}{|c|c|c|c|c|c|c|}
\hline & \multirow[b]{2}{*}{ Model } & \multicolumn{2}{|c|}{ Unstandardized Coefficients } & Standardized Coefficients & \multirow[b]{2}{*}{$\mathrm{t}$} & \multirow[b]{2}{*}{ Sig. } \\
\hline & & $\mathrm{B}$ & Std. Error & Beta & & \\
\hline \multirow[t]{3}{*}{1} & (Constant) & 154869.409 & 116090.637 & & 1.334 & .191 \\
\hline & First Diff. EXP & 2.068 & .191 & .896 & 10.854 & .000 \\
\hline & Residual Lag 1 & -.809 & .154 & -.433 & -5.248 & .000 \\
\hline
\end{tabular}

a. Dependent Variable: First Diff. GDP

Table 10: Coefficients for regression of first-differenced GDP on first diff. EXP and lag 1 Residuals.

From the tables above, the corrected model is $\Delta G D P_{t}=154869.409+2.068 \Delta E X P_{t}-0.809 u_{t-1}$. It can be observed from the table of coefficients that $\alpha_{2}$ (the equilibrium error term) is significant. This indicates that GDP does not adjust to change in EXP in the same time period. The regression model obtained also shows that the short-run changes in EXP have a positive impact on the short run changes in GDP.

\section{Conclusion}

It can be concluded that the residuals from the regression of GDP on EXP are I(0). Hence, the regression model $G D P_{t}=-52730.936+2.759 E X P_{t}$ is not spurious, even though individually, the two variables are non-stationary. Therefore, the regression model is a cointegrating regression and its parameters can be interpreted as long run parameters and hence, the model specified for their relationship will be stable for control action and prediction purpose. In correcting for error with regression model $\Delta G D P_{t}=154869.409+2.068 \Delta E X P_{t}-0.809 u_{t-1}$, it can be observed from the table of coefficients that $\alpha_{2}$ (coefficient of $u_{t-1}$ ), the equilibrium error term is significant. This indicates that GDP does not adjust to change in EXP in the same time period. The regression model obtained also shows that the short-run changes in EXP have a positive impact on the short run changes in GDP.

\section{References}

[1]. Amzath A.; Shen Y.; and Herve D. B. G. (2010): The Effects of Real Exchange Rate on Trade Balance in Cote D'Ivoire: Evidence from The Cointegration Analysis and Error-Correction Models, Journal of Applied Research in Finance (JARF) (1(3)/2010), pp 4460

[2]. Dickey, D. A. and Fuller, W. A. (1979): Distribution of the Estimator for Autoregressive Time Series with a Unit Root, Journal of American Statistical Association, vol. 74, pp 427 - 431.

[3]. Drama B. G. H. and Yao S. (2011): The Demand for Money in Cote d'Ivoire: Evidence from the Cointegration Test. International Journal of Economics and Finance, Vol 3, No 1, pp 188-198.

[4]. Engle, R. F. and Granger, C. W. J. (1987): Co-integration and Error Correction: Representation, Estimation and Testing, Econometrica, vol. 55, pp. $251-276$.

[5]. Fuller W. A. (1976): Introduction to Statistical Time Series, John Wiley \& Sons, New York.

[6]. Granger, C. W. J. (1986): Developments in the study of Co-integrated Economic Variables, Oxford Bulletin of Economics and Statistics, vol. 48, p 226-228.

[7]. Granger, C. W. J. and Newbold, P. (1974): Spurious Regressions in Econometrics, Journal of Econometrics, vol. 2 , pp. 111 - 120.

[8]. Gujarati D. N. and Sangeetha B. (2007): Basic Econometrics, 4th ed., Tata McGraw-Hill, New Delhi.

[9]. Husein, J. (2009): Export-Led Growth Hypothesis: A Multivariate Cointegration and Causality Evidence for Jordan, Journal of Developing Areas, The Spring 2009.

[10]. Johansen, S. and Juselius, K. (1990): "Maximum Likelihood Estimation and Inference on Cointegration, with application to the Demand for Money", Oxford Bulettin of Economics and Statistics 52, pp 169-210

[11]. Pandey, Alok Kumar (2006): Export and Economic Growth in India: Causal Integration, Journal of Global Economy 42 (2006): pp. 245-277.

[12]. Sargan, J. D. (1984): Wages and Prices in the United Kingdom: A study in Econometric Methodology in K. F. Wallis and D. F. Henry, eds., Quantitative Economics and Econometrics Analysis, Basis Blackwell, Oxford.

[13]. Sudhakar S. R. and Jacob K. (2005): Exports and economic growth in India: cointegration, causality and error-correction modeling: a note, Indian Journal of Economics and Business, Vol. 4, No 1, http://www.highbeam.com

[14]. Yule, G. U. (1926): Why Do We Sometimes Get Nonsense Correlations Between Time Series? A Study in Sampling and the Nature of Time Series, Journal of the Royal Statistical Society, vol. 89, pp. $1-64$. 